Archive for

Organic Chemistry

Arkivoc 2018, part iii, 270-278

\title{
Q-Tube (C) assisted MCRs for the synthesis of 2,3-dihydroquinazolin-4(1H)-ones
}

Luca Sancineto, ${ }^{\mathrm{a}}$ Bonifacio Monti, ${ }^{\mathrm{b}}$ Orsola Merlino, ${ }^{\mathrm{b}}$ Ornelio Rosati, ${ }^{\mathrm{b}}$ and Claudio Santi ${ }^{\mathrm{b} *}$

${ }^{a}$ Centre of Molecular and Macromolecular Studies, Polish Academy of Science,

Sienkiewicza 112, 90-363 Łódź Poland

${ }^{b}$ Department of Pharmaceutical Sciences, University of Perugia, via del Liceo 1, 06100 Perugia Italy

Email: claudio.santi@unipg.it

Received 01-29-2018

Accepted 03-15-2018

Published on line $04-29-2018$

\section{Abstract}

A Q-tube assisted, efficient method for the preparation of 2-phenylquinazolin-4-ones is here presented. The target structures were prepared through the one-pot, multicomponent reaction between isatoic anhydride, an aromatic aldehyde and a primary amine following a catalyst-free approach. The use of the commercially available Q-tube $\subseteq$ apparatus allowed to perform reactions at external temperature higher to the solvent boiling point generating medium pressure conditions, shortening the reaction times and affording good yields in all the example herein reported.

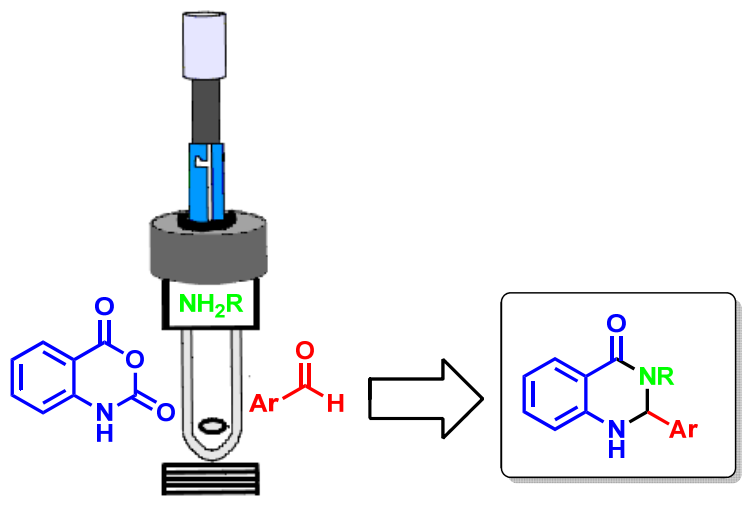

Keywords: 2,3-Dihydroquinazolin-4(1H)-ones, 2-phenylquinazolin-4-ones, Q-tube, isatoic anhydride, chemoselectivity 


\section{Introduction}

Quinazolinone scaffolds, either in the reduced (compound I, 2,3-dihydroquinazolin-4(1H)-one) or in the oxidized (compound II, quinazolin-4(3H)-one) form, are widely distributed in biologically relevant molecules (Figure 1).

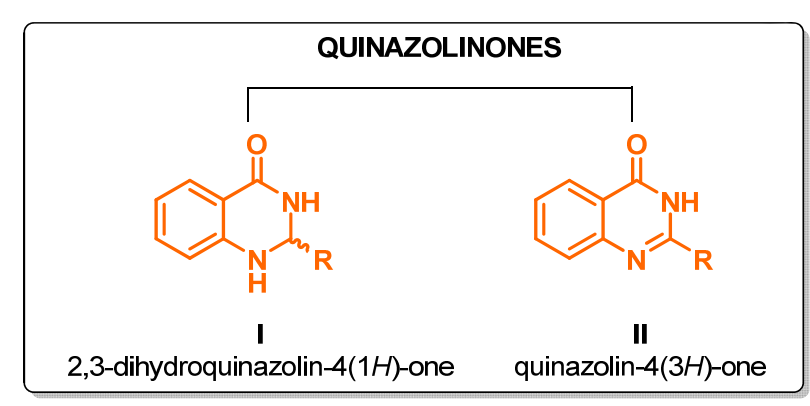<smiles>Cc1ccccc1N1C(=O)c2cc(S(N)(=O)=O)c(Cl)cc2NC1C</smiles><smiles>CC[C@@H]1NC(=O)c2cc(S(N)(=O)=O)c(Cl)cc2N1</smiles><smiles>NS(=O)(=O)c1cc2c(cc1Cl)NC(c1ccccc1)NC2=O</smiles><smiles>O=C1NC(c2ccc(Nc3nc(N4CCCCC4)nc(N4CCCCC4)n3)cc2)Nc2ccccc21</smiles>

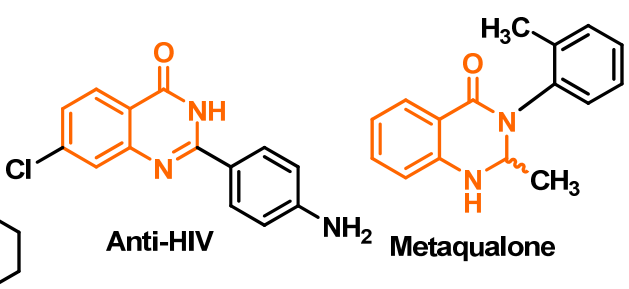
Antileishmania<smiles>COc1cc2nc(N3CCN(C(=O)c4ccco4)CC3)nc(N)c2cc1OC</smiles>

Figure 1. Drugs and pharmacologically relevant molecules characterized by the quinazoline scaffold.

The quinazolinone scaffold characterizes the marketed diuretic drugs Metazolone, Quinetazone and Fenquizone that are currently used to treat hypertension and related diseases or congestive heart failure. ${ }^{1}$ In the antimicrobial research field, some anti leishmanial ${ }^{2}$ and antiviral derivatives ${ }^{3}$ have been developed very recently, the latters through a fragment based drug discovery approach. ${ }^{4}$ Methaqualone, marketed using the brand name of Quaalude is a sedative and hypnotic medication widely used in US also, regrettably, as substance of abuse. ${ }^{5}$ The synthesis of the first in class, anti-hypertensive drug Prazosin and its congeners entails, as key step, the preparation of the quinazoline scaffold which is then converted into the 4-amino quinazoline core by a tree-step procedure. ${ }^{6}$

As a result of the pharmacological importance, a plethora of synthetic methodologies for the preparation of these privileged scaffolds have been reported and are summarized in Scheme 1..$^{-9}$ 


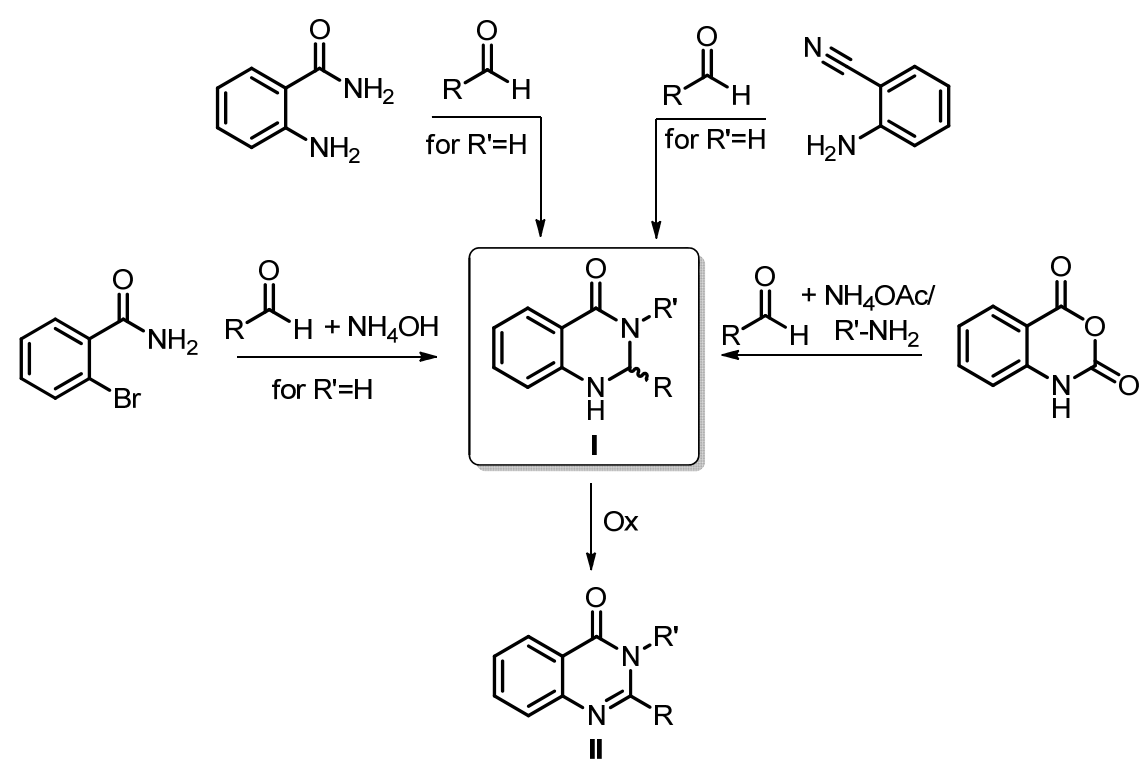

Scheme 1. General procedure for the preparation of Quinazolinones.

All the reported procedures first entailed the preparation of the reduced quinazolinone I which is then converted into the corresponding oxidized form II. In many cases it is impossible to prevent the oxidation reaction thus the compounds having the $\mathrm{C} 2$ with a $\mathrm{sp}^{3}$ hybridization represent per se a synthetic target. The literature survey revealed that the synthetic methodologies could be clustered into 4 groups. In the first one 2aminobenzamide is cyclo-condensed with aromatic and aliphatic aldehydes, ${ }^{10}$ or rarely with substituted benzyl alcohols ${ }^{11}$ or gem-dibromomethylarenes. ${ }^{12}$ Recently, also 2 -aminobenzonitrile was used as a starting point in a green procedure for the preparation of quinazolinones. The reactions took place in presence of aromatic aldehydes in water with $\mathrm{K}_{3} \mathrm{PO}_{4}$ as inorganic base leading to the preparation of various products. ${ }^{13}$

Among the MCRs, in 2014 Guo and co-workers reported the synthesis of the target compounds I starting from 2-bromobenzamide, which reacted with aldehydes and aqueous ammonia in DMSO for $24 \mathrm{~h}$. In principle, this approach is suited for the modification of the $\mathrm{N}-3$ position by replacing ammonium hydroxide with a different primary amine, nevertheless the authors reported just the use of the inorganic amine to selectively obtain compounds II. ${ }^{14}$ Isatoic anhydride is the elective starting material for a multicomponent approach because it gives the possibility to introduce 3 points of diversity in the desired final structures $\left(R_{1}, R_{2}\right.$ and $R_{3}$ in Scheme 2).

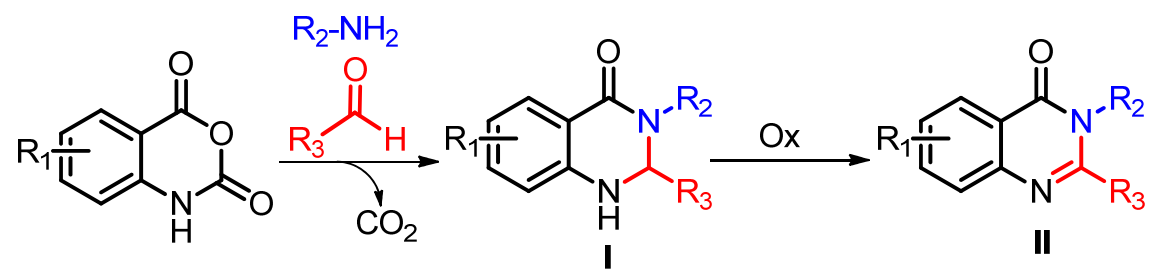

Scheme 2. Synthesis of quinazolinone starting from isatoic anhydride. 
The commonly used methodology entails the treatment of isatoic anhydride with an aldehyde, a primary amine or an ammonium salt under basic conditions. In one case the Lewis acid gallium triflate was used to catalyse the reaction. ${ }^{15}$ As previously stated, the selective synthesis of type I compounds is not easy and often the reaction mixtures contain, beside the desired products also appreciable amounts of the oxidized derivatives II. For this reason, in most of the reported procedures a mild oxidant, such as iodine or DMSO, is used to force the reaction directly to the oxidated product II without even attempting to isolate the reduced intermediate $\mathbf{I}$.

Here we report the Q-Tube mediated, one pot, multicomponent procedure for the selective preparation of compounds I, under mild conditions. The protocol is straightforward and affords the quantitative conversion of the starting material into the target products. The use of the Q-Tube technology permits to exceed the solvent boiling point thus shortening the reaction times. ${ }^{16}$

\section{Result and Discussion}

We started the investigations exploring the best combination solvent/temperature for the reaction between isatoic anhydride 1, benzaldehyde 3a and ammonium acetate 2 in a ratio 1:1:1.5 in the presence of a catalytic amount of the Lewis acid niobium oxide, as prosecution of our interest in exploring the reactivity of this scarcely studied catalyst.

Table 1

\begin{tabular}{cccccccc} 
& & & & & \\
\hline
\end{tabular}

aConversions were determined by ${ }^{1} \mathrm{H}-\mathrm{NMR}$ based on the consumption of the aldehyde. Yields are referred to the amount of $\mathbf{4 b} \mathbf{b} \mathbf{5 b}$ recovered as pure mixture after workup without further purification ${ }^{b}$ see reference $15 .{ }^{c}$ Temperature of the oil bath. ${ }^{d}$ PFPAT= Pentafluorophenylammonium Triflate. 
The reaction in refluxing EtOH (entry 1 ) as well as in DMSO at room temperature under sonication (entry 2) did not produce the desired product. Nevertheless, the reactivity in DMSO resulted nicely controlled by temperature since at $50^{\circ} \mathrm{C}, 100^{\circ} \mathrm{C}$, and $170^{\circ} \mathrm{C}$ the formation of $4 \mathrm{a}: 5 \mathrm{a}$ was obtained in traces, $89 \%$ and $91 \%$, respectively (entries 3, 5 and 6 ) allowing, in the latter case, to reduce the reaction time at $1.5 \mathrm{~h}$. The chemoselectivity resulted to be dependent on the temperature, as well. The almost complete formation of $\mathbf{5 a}$ was observed at $100^{\circ} \mathrm{C}$ whereas at $170^{\circ}$ the oxidized form $4 \mathrm{a}$ was detected in a $4 \mathrm{a} / 5 \mathrm{a}$ ratio of $23: 77$. We also investigated the possibility to use ultrasounds for the activation of the reaction at lower temperature without appreciable improvements (entry 4). We proved that at $170^{\circ} \mathrm{C}$ the catalysis of niobium oxide is minimal, discouraging its use for a better atom economy of the entire process (see entry 6 vs entry 7). Several different solvents were also tested and, at the same time, a Q-Tube $\subset$ device was used to perform reactions at external temperatures higher than those of the solvents boiling point and under medium pressure conditions. DMF and water did not afford desired product whereas using toluene in Q-Tube $\subset$ in an oil bath at $170^{\circ} \mathrm{C} 2$ phenylquinazolin-4-one $\mathbf{5 a}$ was obtained in $90 \%$ yield (entry 11 ). In toluene, Q-tube $\bigodot$ allowed to avoid the use of catalysts, reducing reaction time, yielding the target compound in 1.5 hours rather than 3 hours, as reported in literature for refluxing conditions (entry 11 and 12). ${ }^{17}$ In addition the solvent can be recovered by distillation in its pure form (confirmed by ${ }^{1} \mathrm{H}-\mathrm{NMR}$ analysis) and reused for subsequent reactions, reducing waste production and the issues connected with the toxicity and environmental risks.
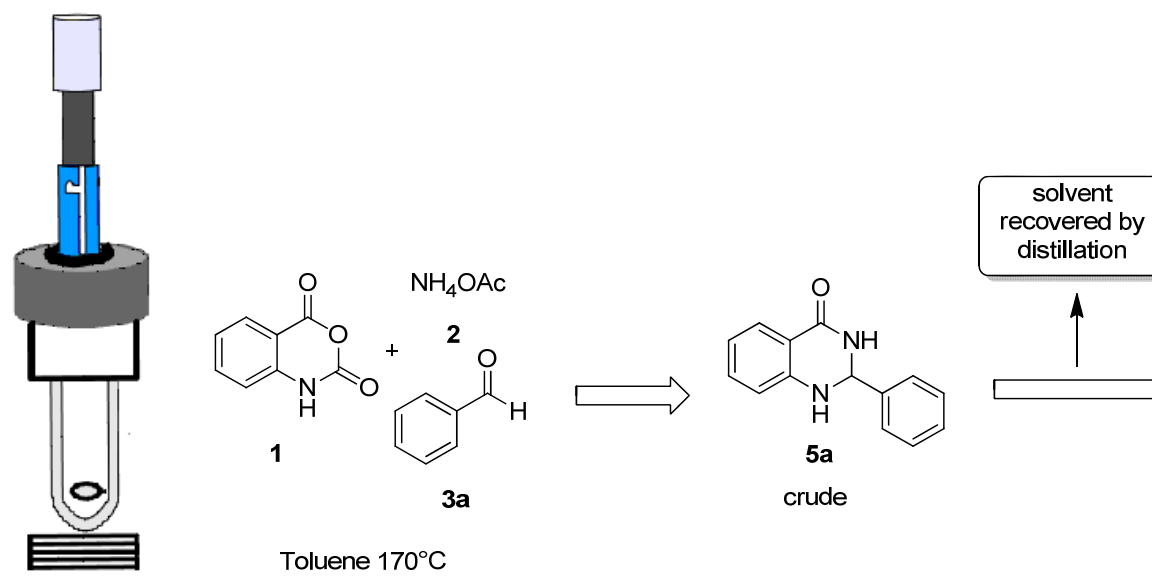

Scheme 3. General reaction setup.

A similar comparison of the different reaction conditions has been performed starting from $p$ chlorobenzaldehyde $\mathbf{3 b}$ and the results are summarized in Table 2.

In this case, the catalytic effect of $\mathrm{Nb}_{2} \mathrm{O}_{5}$ is slightly evident in DMSO at $170{ }^{\circ} \mathrm{C}$ (entry 1 vs entry 2). The use of the Q-tube (C) continues to be superior affording in 1.5 hours $\mathbf{5 b}$ in $98 \%$ yield without catalyst (Table 2, entry 4) affording better results in comparison with the refluxing conditions in the presence of pentafluorophenylammonium triflate as catalyst.

Having elected as the best conditions those depicted in Table 1 entry 12, we explored the scope of the reaction. As reported in Table 3 entries 1-6, aldehydes bearing both electron donating and withdrawing groups were tested indicating that the nature of substituent did not influence the yield that, in all the cases, are very good. On the contrary, the chemoselectivity appear to be influenced by the electronic properties of substituents: the electron-withdrawing effect of halogens facilitates the exclusive formation of compound $\mathbf{5 b}$, 
5e while the methoxy group favours the oxidation reaction leading to a mixture of $4 c: 5 c$ in both toluene and DMSO (Table 3, entry 5 and 6).

Table 2<smiles>NC(=O)[O-]</smiles>

1<smiles>O=Cc1ccc(Cl)cc1</smiles>

$3 b$<smiles>O=c1[nH]c(-c2ccc(Cl)cc2)nc2ccccc12</smiles>

4b<smiles>O=C1NC(c2ccc(Cl)cc2)Nc2ccccc21</smiles>

\begin{tabular}{|c|c|c|c|c|c|c|c|}
\hline Entry & Solvent & $\mathrm{T}\left({ }^{\circ} \mathrm{C}\right)$ & $1: 2: 3 b$ & Cat (mol \%) & Yield (\%) & $4 b: 5 b$ & Time (h) \\
\hline 1 & DMSO & 170 & 1:1.5:1 & $\mathrm{Nb}_{2} \mathrm{O}_{5}(10 \%)$ & 91 & $25: 75$ & 1.5 \\
\hline 2 & DMSO & 170 & 1:1.5:1 & -- & 78 & $23: 77$ & 1.5 \\
\hline 3 & THF & 170 (Q-tube) $^{\mathrm{e}}$ & 1:1.5:1 & -- & 73 & $1: 99$ & 1.5 \\
\hline 4 & Toluene & $170{\text { (Q-Tube })^{\mathrm{e}}}^{\mathrm{e}}$ & 1:1.5:1 & -- & 98 & $1: 99$ & 1.5 \\
\hline $5^{b}$ & Toluene & reflux & 1:1.2:1 & PFPAT $(10 \%)^{c}$ & 95 & n.r. ${ }^{d}$ & 3 \\
\hline
\end{tabular}

${ }^{a}$ Conversions, determined by ${ }^{1} \mathrm{H}-\mathrm{NMR}$ based on the consumption of the aldehyde, were in all the cases quantitative. Yields are referred to the amount of $\mathbf{4 b}+\mathbf{5 b}$ recovered as pure mixture after workup without further purification purification ${ }^{b}$ Reference $15^{c}$ PFPAT: Pentafluorophenylammonium Triflate. ${ }^{d}$ Not reported. ${ }^{e}$ Temperature of the oil bath.

\section{Table 3}<smiles>O=c1[nH]c2ccccc2c(=O)o1</smiles>

1<smiles>[R]c1ccc(C=O)cc1</smiles>

3a $\mathrm{R}=\mathrm{H}$ 3b R=Cl 3c $\mathrm{R}=\mathrm{OMe}$ 3d R=NO 3e $R=F$,

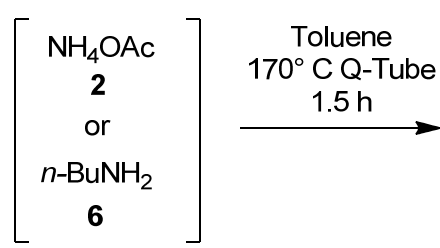

$170^{\circ} \mathrm{C} \mathrm{Q}$-Tube
$1.5 \mathrm{~h}$<smiles>[R]c1ccc(-c2nc3ccccc3c(=O)n2[R])cc1</smiles>

4a $\mathrm{R}=\mathrm{H}, \mathrm{R}^{\prime}=\mathrm{H}$ 4b $\mathrm{R}=\mathrm{Cl}, \mathrm{R}^{\prime}=\mathrm{H}$

4c $\mathrm{R}=\mathrm{OMe}, \mathrm{R}^{\prime}=\mathrm{H}$

4d R=NO $2, \mathrm{R}^{\prime}=\mathrm{H}$

4e $\mathrm{R}=\mathrm{F}, \mathrm{R}^{\prime}=\mathrm{H}$

$7 \mathrm{R}=\mathrm{Cl}, \mathrm{R}^{\prime}=n-\mathrm{Bu}$<smiles>[R]c1ccc(C2Nc3ccccc3C(=O)N2[R])cc1</smiles>

5a $\mathrm{R}=\mathrm{H}, \mathrm{R}^{\prime}=\mathrm{H}$

5b $\mathrm{R}=\mathrm{Cl}, \mathrm{R}^{\prime}=\mathrm{H}$

5c $\mathrm{R}=\mathrm{OMe}, \mathrm{R}^{\prime}=\mathrm{H}$

5d R=NO ${ }_{2}, \mathrm{R}^{\prime}=\mathrm{H}$

5e $\mathrm{R}=\mathrm{F}, \mathrm{R}^{\prime}=\mathrm{H}$

$8 \mathrm{R}=\mathrm{Cl}, \mathrm{R}^{\prime}=\mathrm{Bu}$

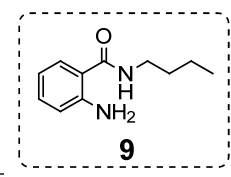

$4: 5$

$1: 99$

$1: 99$

$1: 99^{b}$

$30: 70$

$20: 80$

88

$0: 100^{\mathrm{d}}$ 
${ }^{a}$ Conversions, determined by ${ }^{1} \mathrm{H}-\mathrm{NMR}$ based on the consumption of the aldehyde, were in all the cases quantitative. Yields are referred to the amount of $\mathbf{4 b + 5 b}$ recovered as pure mixture after workup without further purification excepted where otherwise indicated ${ }^{b}$ Some other impurities $(<10 \%)$ are present and cannot be removed due to the instability of $\mathbf{5 d}$. ${ }^{c}$ Reaction was performed in DMSO at $170^{\circ} \mathrm{C}$ and $10 \mathrm{~mol} \%$ $\mathrm{Nb}_{2} \mathrm{O}_{5}$ was used. ${ }^{\mathrm{d}} 40 \%$ of the amide 9 was recovered. ${ }^{e}$ Isolated yield by chromatography

In the case of the nitro aldehyde $\mathbf{3 d}$ the corresponding $\mathbf{5 d}$ was obtained almost quantitatively as proved by the ${ }^{1} \mathrm{H}-\mathrm{NMR}$ analysis of the crude, but it was impossible to isolate in pure form due to its instability. In one example, ammonium acetate was replaced with $n$-butylamine $\mathbf{6}$, giving the target compound $\mathbf{8}$ in moderate yield but in mixture with the butyl-substituted anthranilamide $\mathbf{9}$. The isolation of this intermediate gives some information about a plausible reaction mechanism and can be supposed that, in this case, after isatoic anhydride decomposition and the formation of $\mathbf{9}$, the butyl substituent exerts a steric hindrance that disfavours the successive condensation reaction with the aldehyde.

\section{Conclusions}

In conclusion we described the possibility to use the Q-tube (C) apparatus to promote the chemoselective synthesis of 2,3-dihydroquinazolin- $4(1 \mathrm{H})$-ones skeletons starting from isatoic anhydride without any catalyst or additive. The organic solvent used for the synthesis can be recovered and reused reducing the environmental issues correlated to the use of toluene.

\section{Experimental Section}

General. Reactions were conducted in Q-tube ${ }^{\bullet}$ and were stirred with Teflon-coated magnetic stirring bar. Solvents and reagents were used as received unless otherwise noted. Analytical thin layer chromatography (TLC) was performed on silica gel 60 F254 pre-coated aluminium foil sheets and visualized by UV irradiation or by use of a $\mathrm{KMnO}_{4}$ stain. Silica gel Kieselgel 60 (70-230 mesh) was used for column chromatography. NMR experiments were obtained at $25^{\circ} \mathrm{C}$ on a Bruker DPX 200 spectrometer operating at $200 \mathrm{MHz}$ for ${ }^{1} \mathrm{H}$ and 50.31 $\mathrm{MHz}$ for ${ }^{13} \mathrm{C}$ experiments or in a Bruker DRX spectrometer operating at $400 \mathrm{MHz}$ for ${ }^{1} \mathrm{H}$ and $50.31 \mathrm{MHz}$ for ${ }^{13} \mathrm{C}$ experiments. ${ }^{1} \mathrm{H}$ and ${ }^{13} \mathrm{C}$ chemical shifts $(\delta)$ are reported in parts per million (ppm) and they are relative to TMS $0.0 \mathrm{ppm}$ and the residual solvent peak of DMSO- $\mathrm{d}_{6}$ at $\delta 2.54$ and $\delta 40.45$ in ${ }^{1} \mathrm{H}$ and ${ }^{13} \mathrm{C} \mathrm{NMR}$, respectively. Data are reported as follows: chemical shift (multiplicity, number of hydrogens, coupling constants where applicable, and assignment where possible). Abbreviations are as follows: $s$ (singlet), $d$ (doublet), $t$ (triplet), $q$ (quartet), dd (doublet of doublet), $d t$ (double of triplet), tt (triplet of triplet), m (multiplet), bs (broad signal). Coupling constant $(\mathrm{J})$ quoted in Hertz $(\mathrm{Hz})$ to the nearest $0.1 \mathrm{~Hz}$. All the starting material are commercially available.

General procedure for synthesis of $\mathbf{2 H}$-quinazolin-4-one 5 a-e and 8 . Q-tube is charged with isatoic anhydride 1 (150 mg, $0.919 \mathrm{mmol}$ ), ammonium acetate $2(106 \mathrm{mg}, 1.378 \mathrm{mmol}$ ) to obtain compounds $5 a-e$, or $n$ butylamine $6(137 \mu \mathrm{L}, 1.378 \mathrm{mmol})$ to obtain compound $\mathbf{8}$, aldehyde 3a, 3b, 3c, 3d, 3e $(0.919 \mathrm{mmol})$ with 0.8 $\mathrm{mL}$ of toluene. The reaction mixture is than vigorously stirred at $170{ }^{\circ} \mathrm{C}$ for 1.5 hour. After cooling at room 
temperature, the solvent was recovered by distillation and the crude residue was diluted with water (15 ml) and extracted three times with EtOAc $(3 \times 15 \mathrm{ml})$. The organic layers were dried using $\mathrm{Na}_{2} \mathrm{SO}_{4}$ and then evaporated under reduced pressure. Crude products starting from $3 c$ were purified by chromatographic column affording $\mathbf{5 c}$ and $\mathbf{8}$, in all the other cases the target compounds were obtained after workup as a pure mixture of $\mathbf{4}$ and $\mathbf{5}$ in the ratios reported in the Tables. Spectral data for all the compounds agree with those reported in literature and for the major products, ${ }^{1} \mathrm{H}$ NMR and selected examples of ${ }^{13} \mathrm{C}$ and ${ }^{19} \mathrm{~F}$ NMR spectra, extrapolated from the mixture, are reported below.

2-Phenyl-2,3-Dihydroquinazolin-4(1H)one (5a). ${ }^{1} \mathrm{H}-\mathrm{NMR}$ (DMSO- $\mathrm{d}_{6}, 400 \mathrm{MHZ}$ ): $\delta 8.31(\mathrm{~s}, 1 \mathrm{H}), 7.63(\mathrm{~d}, 1 \mathrm{H}, \mathrm{J} 7.2 \mathrm{~Hz}$ ), $7.50(\mathrm{~d}, 2 \mathrm{H}, \mathrm{J} 6.9 \mathrm{~Hz}), 7.38-7.42(\mathrm{~m}, 3 \mathrm{H}), 7.24-7.26(\mathrm{~m}, 1 \mathrm{H}), 7.13(\mathrm{~s}, 1 \mathrm{H}), 6.75(\mathrm{~d}, 1 \mathrm{H}, \mathrm{J} 8.0 \mathrm{~Hz}), 6.68(\mathrm{t}, 1 \mathrm{H}, \mathrm{J} 7.3 \mathrm{~Hz})$, $5.76(\mathrm{~s}, 1 \mathrm{H}) \mathrm{ppm}$. Physical data agree with those reported in literature. ${ }^{13}$

2-(4-chlorophenyl)-dihydroquinazolin-4(1H)one (5b). ${ }^{1} \mathrm{H}-\mathrm{NMR}$ (DMSO-d, $200 \mathrm{MHZ}$ ): $\delta 8.39$ (s, $1 \mathrm{H}$ ), 7.63 (dd, $2 \mathrm{H}, \mathrm{J}$ 1.6, $7.7 \mathrm{~Hz}), 7.54(\mathrm{~m}, 3 \mathrm{H}), 7.29(\mathrm{t}, 1 \mathrm{H}), 7.19(\mathrm{~s}, 1 \mathrm{H}), 6-68-6.79(\mathrm{~m}, 2 \mathrm{H}), 5.80(\mathrm{~s}, 1 \mathrm{H}) \mathrm{ppm}$. Physical data agree with those reported in literature. ${ }^{13}$

2-(4-Methoxyphenyl)-dihydroquinazolin-4(1H)one (5c). 30\% yield after chromatographic purification using as eluent Ethyl acetate/petroleum ether (8:2). ${ }^{1} \mathrm{H}-\mathrm{NMR}$ (DMSO-d $\mathrm{d}_{6}, 400 \mathrm{MHZ}$ ): $\delta 8.15$ (s, $1 \mathrm{H}$ ), 7.59 (d, $\left.1 \mathrm{H}, \mathrm{J} 7.7 \mathrm{~Hz}\right), 7.40$ (d, $2 \mathrm{H}, \mathrm{J}$ $8.6 \mathrm{~Hz}$ ), $7.21(\mathrm{t}, 1 \mathrm{H}, \mathrm{J} 13.9 \mathrm{~Hz}), 7.00(\mathrm{~s}, 1 \mathrm{H}), 6.93(\mathrm{~d}, 2 \mathrm{H}, \mathrm{J} 8.6 \mathrm{~Hz}), 6.72(\mathrm{~d}, 1 \mathrm{H}, \mathrm{J} 8.0 \mathrm{~Hz}), 6.66(\mathrm{t}, 1 \mathrm{H}, \mathrm{J}$ 14.8), $5.69(\mathrm{~s}, 1 \mathrm{H})$ ppm. Physical data agree with those reported in literature. ${ }^{13}$

2-(4-Nitrorophenyl)-dihydroquinazolin-4(1H)one (5d). ${ }^{1} \mathrm{H}-\mathrm{NMR}$ (DMSO- $\left.\mathrm{d}_{6}, 400 \mathrm{MHz}\right): \delta 8.62(\mathrm{~s}, 1 \mathrm{H}) ; 8.30-8.25(\mathrm{~m}, 2 \mathrm{H})$; 7.80-7.75 (m,2H) ; $7.65(\mathrm{dd}, 1 \mathrm{H}, \mathrm{J} 1.5$ and $9.9 \mathrm{~Hz}) ; 7.30(\mathrm{~s}, 1 \mathrm{H}) ; 7.25 \mathrm{dt}, 1 \mathrm{H}, \mathrm{J} 1.7 \mathrm{and} 8.2 \mathrm{~Hz}) ; 6.61-6.39(\mathrm{~m}, 2 \mathrm{H} ; 6.05(\mathrm{t}$, $1 \mathrm{H}, \mathrm{J} 2.2 \mathrm{~Hz}$ ) Physical data agree with those reported in literature. ${ }^{15}$

2-(4-Fluorophenyl)-dihydroquinazolin-4(1H)one (5e). ${ }^{1} \mathrm{H}-\mathrm{NMR}$ (DMSO- $\mathrm{d}_{6}, 400 \mathrm{MHz}$ ): $\delta 8.29(\mathrm{~s}, 1 \mathrm{H}$ ), $7.58(\mathrm{~d}, 1 \mathrm{H}, \mathrm{J} 7.3$ $\mathrm{Hz})$, 7.50-7.54 (m, $2 \mathrm{H}, \mathrm{J} 8.4 \mathrm{~Hz}$ ), 7.21-7.25 (m, $3 \mathrm{H}), 7.09(\mathrm{~s}, 1 \mathrm{H}), 6.72(\mathrm{~d}, 1 \mathrm{H}, \mathrm{J} 7.8 \mathrm{~Hz}), 6.67(\mathrm{t}, 1 \mathrm{H}, \mathrm{J} 14.9 \mathrm{~Hz}), 5.75(\mathrm{~s}, 1$ H) ppm. ${ }^{13}$ C-NMR (DMSO-d $\left.60.31 \mathrm{MHz}\right): 65.93,114.68(\mathrm{~d}, \mathrm{~J} 22.64 \mathrm{~Hz}), 114.91,115.34,117.28,127.38,129.07$ (d, J 8.55 $\mathrm{Hz}$ ), 133.39, 137.83, 147.86, 162.17 (d, J $244.00 \mathrm{~Hz}$ ), $163.58{ }^{19} \mathrm{~F}-\mathrm{NMR}$ (DMSO-d 6 , $376 \mathrm{MHz}$ ): $114.29 \mathrm{ppm}$. Physical data agree with those reported in literature. ${ }^{18}$

3-Butyl-2-(4-chlorophenyl)-2,3-dihydroquinazolin-4(1H)one(8). Purified eluting with petroleum ether/ethyl acetate (7:3). ${ }^{1} \mathrm{H}-\mathrm{NMR}$ (DMSO-d $\left.6,400 \mathrm{MHz}\right): \delta 7.64(\mathrm{~d}, 1 \mathrm{H}, \mathrm{J}$ 7.8 Hz), 7.33-7.43 (m, $5 \mathrm{H}), 7.19-7.22(\mathrm{~m}, 1 \mathrm{H})$, 6.62-6.68 $(\mathrm{m}, 2 \mathrm{H})$, $5.87(\mathrm{~s}, 1 \mathrm{H}), 3.87-3.94(\mathrm{~m}, 1 \mathrm{H}), 2.71-2.77(\mathrm{~m}, 1 \mathrm{H}), 1.43-1.57(\mathrm{~m}, 2 \mathrm{H}), 1.24-1.31(\mathrm{~m}, 3 \mathrm{H}), 0.84-0.98(\mathrm{~m}, 3 \mathrm{H}) \mathrm{ppm}$. Physical data agree with those reported in literature. ${ }^{14}$

\section{Acknowledgements}

University of Perugia and the "Fondo Ricerca di Base 2017" are warmly acknowledged. Authors also thanks CBMM (Companhia Brasileira de Metalurgia e Mineração) that provided Niobium oxide. L.S. acknowledges for the financial support from the Polish National Science Centre (Polonez 2 (Reg. No: 2016/21/P/ST5/ 03512)).

\section{References}

1. Malhotra V.; Nath, R.; Shanker, K.; Pathak, S.R.; Central Nervous System Agents in Medicinal Chemistry, 2014,14, 3438.

https://doi.org/10.2174/1871524914666140825144729 
2. Sharma, M.; Chauhan, K.; Shivahare, R.; Vishwakarma, P.; Suthar, M. K.; Sharm, A.; Gupta, S.; Saxena, J. K.; Lal, J.; Chandra, P.; Kumar, B.; Chauhan, P. M. S.; J. Med. Chem. 2013, 56, 4374-4392 https://doi.org/10.1021/jm400053v

3. Sancineto, L.; Iraci, N.; Massari, S.; Attanasio, V.; Corazza, G.; Barreca, M. L.; Sabatini, S.; Manfroni, G.; Avanzi, N. R.; Cecchetti, V.; Pannecoque, C.; Marcello, A.; Tabarrini, O.; ChemMedChem 2013, 8, 1941-1953. https://doi.org/10.1002/cmdc.201300287

4. Sancineto, L.; Massari, S.; Iraci, N.; Tabarrini, O.; Current Medicinal Chemistry 2013, 20, 1355-1381. https://doi.org/10.2174/09298673113209990111

5. Gilson, A. M.; Ryan, K. M.; Joranson, D. E.; Dahl, J. L.; J. Pain and Symptom Management 2004, 28, 176-188. https://doi.org/10.1016/j.jpainsymman.2004.01.003

6. Merck Index, Thirteenth Ed., Merck Publishing Group: Rahway, NJ, 2001; No. 7803,

7. Reddy, P. P.; Vasantha, T.; Reddy, P. S. Heterocycles 2003, 60, 183-226. https://doi.org/10.3987/REV-01-540

8. Dabiri, M.; Salehi, P.; Otokesh, S.; Baghbanzadeh, M.; Kozehgary, G.; Mohammadi, A. A. Tetrahedron Lett. 2005, 46, 6123-6126 https://doi.org/10.1016/i.tetlet.2005.06.157

9. Baghbanzadeh, M.; Salehi, P.; Dabiri, M.; Kozehgary, G. Synthesis 2006, 2, 344-348.

10. Chen, J.; Su, W.; Wu, H.; Liu, M.; Jin, C. GreenChem 2007,9,972-975. https://doi.org/10.1039/b700957g

11. Sharif, M.; Opalach, J.; Langer, P.; Beller, M.; Feng-Wu, X.; RSC Adv. 2014, 4, 8-17. https://doi.org/10.1039/C3RA45765F

12. Narasimhamurthy, K. H.; Chandrappa, S.; Kumar, S. K. S.; Harsha, K.; Ananda, H.; Rangappa, K.S.; RSC Adv. 2014,4, 34479-34486. https://doi.org/10.1039/C4RA02312A

13. Feng Wu, X.; Oschatz, S.; Block, A.; Spannenberg, A.; Langer, P.; Org. Biomol. Chem. 2014, 12, 1865-1870. https://doi.org/10.1039/c3ob42434k

14. Guo, S.; Li, Y.; Tao, L.; Zhang, W.; Fan, X.; RSC Adv. 2014, 4, 59289-59296. https://doi.org/10.1039/C4RA10799C

15. Chen, J.; Wu, D.; He, F.; Liu, M.; Wu, H.; Ding, J:; Su, W.; Tetrahedron Lett. 2008, 49, 3814-3818. https://doi.org/10.1016/j.tetlet.2008.03.127

16. Nacca, F. G.; Merlino, O.; Mangiavacchi, F.; Krasowska, D.; Santi, C.; Sancineto, L.; Current Green Chemistry 2017, 4, 58-66.

17. Khaksar, S.; Gholami, M.; Res. Chem. Intermed. 2015, 41, 3709-3718. https://doi.org/10.1007/s11164-013-1483-7

18. Shaabani, A.; Maleki, A.; Mofakham,H.; Synth. Commun. 2008, 38, 3751-3759. https://doi.org/10.1080/00397910802213802 